\title{
JARDINES DUPLICADOS EN LAS COMEDIAS MITOLÓGICAS DE CALDERÓN
}

\author{
María Isabel Rodríguez Romera \\ UNED (Universidad Nacional de Educación a Distancia) \\ Facultad de Filología \\ Apdo. de correos 60.145 \\ 28080 Madrid. España \\ mariaisabel.rdrgz@gmail.com
}

Cuando el artista traza el espacio y sugiere así el camino que sigue la imaginación en su exégesis del universo, lo hace partiendo de un contexto que asigna a cada lugar un valor determinado. Amezcua afirma que los espacios tienen en el Barroco una raíz antitética, fundada en las dos parejas "afuera-adentro» y "arriba-abajo" ${ }^{1}$, visión que se completa con "próximo-lejano", de menor relieve. Sin embargo, añade que en Calderón lo verdaderamente interesante es analizar los cambios que experimentan los espacios durante la acción, pues ese distanciamiento de lo convencional es «una de las vertientes donde fluye libremente la ideología del autor $\aleph^{2}$. De acuerdo con esta idea, Arellano explica cómo el dramaturgo, en «ámbitos profanos», a veces transgrede los valores tra-

\footnotetext{
${ }^{1}$ Acerca de esta segunda dicotomía aplicada a lo terrenal y lo celeste, de gran rendimiento en Calderón, ver Cancelliere, 2001.

${ }^{2}$ Amezcua, 1983, p. 1541.

RECEPCIÓN: 20.07.15 / ACEPTACIÓN DEFINITIVA: 30.09 .15

[Anuario Calderoniano (ISSN: 1888-8046), 9, 2016, pp. 177-194]
} 
dicionales de los lugares, lo que descubre el «sentido de una acción o el carácter de un personaje» ${ }^{3}$.

En las comedias mitológicas, Calderón teje las intrigas de humanos, héroes y dioses que habitan lugares de tiempos remotos, que nos evocan imágenes pictóricas guardadas en la memoria del Barroco. Los espacios, que se nutren de tópicos y conflictos reveladores de su concepto vital, se construyen a partir de un catálogo poético: mar, monte, jardín, palacio y templo. Estos tienen capacidad de rebasar sus límites, albergar otros elementos locativos, como la gruta, y alcanzar la fantasía ${ }^{4}$, situando la acción en el cielo o en el infierno, o atribuyendo cualidades sobrenaturales a los lugares mencionados.

La caracterización del jardín en el Siglo de Oro, lugar contiguo al palacio, la casa o el templo, no responde a un modelo único. Antes bien, comprende desde espacios que surgen como el dominio de la Naturaleza por el Arte, en contraste con el monte, hasta otros más agrestes, con perspectivas abiertas e integradoras de entornos rendidos a las fuerzas de los elementos, de gran eficacia en las comedias mitológicas ${ }^{5}$. La aspereza de los jardines boscosos se deslinda del lirismo de los que remedan el cielo y el mar a través de un juego de reflejos cromáticos y de correlaciones metafóricas que tienen su máxima representación, en el corpus calderoniano, en El príncipe constante, donde el jardín de Fénix es «un mar de flores» y el mar, «un jardín de espumas» ${ }^{6}$.

$\mathrm{Su}$ consideración como uno de los espacios literarios con mayor riqueza simbólica y estética ha despertado el interés de la crítica. A este respecto, Suárez Miramón apunta las vías desde las que se forja su significado y que se condensan en el Barroco: «en el jardín se había sintetizado toda la tradición arcádica del locus amoenus, la pagana del jardín de las Hespérides, la iniciática de Platón, la cristiana del Paraíso y la

\footnotetext{
${ }^{3}$ Arellano, 2001, p. 86. Uno de los ejemplos que se mencionan es la paradójica oposición entre monte y palacio en La vida es sueño, donde Segismundo, al comportarse con más brutalidad en palacio, entorno más civilizado que el monte, recibe un carácter simbólico derivado de estos espacios.

${ }^{4}$ Para los espacios de maravilla en Calderón, ver Arellano, 2003.

${ }^{5}$ Rull, 2011, distingue el «jardín renacentista» o convencional del selvático. El autor ofrece ejemplos de este último no solo en el género y autor que nos ocupan, sino también en la arquitectura y en la pintura de la época. Esta mixtura de bosque y jardín recibe el nombre de «boscarecha», término que, aplicado al teatro mitológico fue registrado con anterioridad en Egido, ed. de La fiera, el rayo y la piedra, 1989, p. 21.

${ }^{6}$ Calderón, El príncipe constante, p. 51, vv. 95-96.
} 
hedonística del jardín de las delicias, sin olvidar la ostentación de poder de quien tenía un bello jardín, pues los ejemplos en la realidad se habían multiplicado y al utilizarlo para teatro permitía aludir a una realidad y al mismo tiempo integrar simbólicamente el proceso de la acción» ${ }^{7}$. El recorrido histórico desvela algunas de las connotaciones del jardín en el teatro áureo: lugar de refugio y de belleza, de maravilla, de reflexión, hortus conclusus, espacio celestial (solo alterable cuando el hombre toma la fruta prohibida $)^{8}$ o espacio para el amor.

Lara Garrido ${ }^{9}$ y Lobato ${ }^{10}$ han profundizado en el motivo del jardín en el teatro barroco y han sistematizado una serie de valores que Alvarado Teodorika ${ }^{11}$ condensa para aplicar su propuesta a las comedias mitológicas de Calderón. La investigadora distingue dos funciones: por un lado, el jardín como «marco de la acción», propicio para el amor, en armonía o en conflicto, y para la reflexión; por otro lado, el jardín «dentro del desarrollo de la acción», que admite la confusión y el enredo, como efecto del deseo o la razón.

Las observaciones precedentes cobran especial interés en las obras que vamos a analizar, donde un jardín inicial queda desplazado por otro cuando el desarrollo de la acción lo imposibilita como marco para el amor. La primera de todas ellas es La fiera, el rayo y la piedra (1652), en la que el palacio y los jardines de Pigmaleón, al final de la tercera jornada, son el lugar de resolución de la trama, tras un proceso de reajuste en los valores del jardín de Anajarte.

La presencia de dos espacios similares en Calderón ya ha sido tratada por Iglesias Feijoo y Hernando Morata ${ }^{12}$ a propósito de Casa con dos puertas mala es de guardar, donde se produce un «desdoblamiento de los espacios domésticos», con las casas de Laura y de Marcela. Además, dichos espacios contienen paralelismos y simetrías, como los celos sufridos primero por Laura y después por Félix. La técnica empleada en esta comedia de capa y espada, de ambiente próximo a La dama duende, la observamos en las otras dos comedias objeto de estudio. En Apolo y

${ }^{7}$ Suárez Miramón, 2006, p. 4.

${ }^{8}$ Acerca del jardín como lugar celestial, ver Zugasti, 2011. El estudio se realiza sobre los autos sacramentales Andrómeda y Perseo y La vida es sueño.

${ }^{9}$ Lara Garrido, 1983, 2000.

${ }^{10}$ Lobato, 2007.

11 Alvarado Teodorika, 2010.

12 Iglesias Feijoo y Hernando Morata, 2013. 
Climene $^{13}$ (1661) la princesa pasa de perseguir un engaño a ser ella la perseguida por una supuesta traición a Diana. En Ni Amor se libra de amor (1662), de una mayor precisión en los símiles estructurales, se nos muestra en la primera jornada a Psiquis, en su jardín, que sorprende a Cupido contemplándola mientras duerme; en la tercera, es Cupido el «bello dormido» ${ }^{14}$ observado por la joven. Pero más allá de constatar la presencia de la misma técnica en las comedias mitológicas mencionadas, hemos de preguntarnos qué conflictos se plantean en sus jardines y qué funciones desempeñan estos espacios, los iniciales y los duplicados.

\section{El jardín vacío de Anajarte}

En La fiera, el rayo y la piedra la acción se genera en torno a Irífile, con la condición de salvaje, y Anajarte, princesa encerrada por su tío Argante para que pueda gobernar su hijo Céfiro. A ellas hay que añadir una estatua que cobra vida al final de la obra. Los tres personajes se emparejan, respectivamente, con Céfiro, Ifis y Pigmaleón, quienes sufrirán la venganza de Cupido por haber actuado con indiferencia en la lucha que mantenía contra Anteros. Las dos damas y la estatua coinciden fisicamente en el jardín de Anajarte, donde vemos un juego de influencias entre espacios y personajes que va restringiendo la simbología de este lugar, hasta hacerle perder su capacidad para acoger el amor.

En la segunda jornada, Irífile se traslada del monte al entorno cortesano y, pese a tener momentos de desvarío, pronto toma conciencia de sus actos y se vuelve más prudente, lo que demuestra una gran facilidad para apropiarse de los lugares que habita: «me parece que entre pompas / reales estoy en mi centro» ${ }^{15}$. Después, le implora a Anajarte: «te ruego / que como a humana me trates / pues lo soy; / que si el despecho / soberbia me hizo en los montes, / humilde me hará el consejo en los poblados $»^{16}$.

A diferencia de Irífile, la supuesta princesa de Trinacria está constreñida a un lugar desvirtuado, un palacio para una no reina, y a una

\footnotetext{
${ }^{13}$ Esta obra presenta otros elementos coincidentes con Casa con dos puertas mala es de guardar y con La dama duende: el tema de la honra y el uso de pasadizos para evitar juicios ajenos.

${ }^{14}$ Acerca de esta imagen, ver Porqueras Mayo, 1983.

${ }^{15}$ Calderón, La fiera, el rayo y la piedra, p. 253, vv. 1704-1705.

${ }^{16}$ Calderón, La fiera, el rayo y la piedra, p. 253, vv. 1709-1714.
} 
pretensión que acaba siendo irrealizable. Si la primera se deslumbra con los objetos de la corte, la segunda lo hace con su albedrío. Los desajustes entre las dos mujeres y sus respectivos lugares de origen nos hacen dudar de las apariencias y nos predisponen a pensar en un trueque entre ellas para que se produzca un equilibrio, anticipación de lo que Anteo revelará al final de la obra.

La acción en la tercera jornada se inicia con una escenografia de monte y jardín. Hacia este último se dirigen Céfiro, en busca de Irífile, y Pigmaleón, en busca de su estatua. Una vez allí, vemos cómo se materializa el propósito de la princesa de erradicar su función como marco ideal para el amor: al echar la estatua al monte no ve «a quien podía / ser objeto de otro amor» ${ }^{17}$. Esto generará una alteración en la composición tradicional de lugares: primero, el jardín de Anajarte es desprovisto de un elemento artístico que pasa a estar en un entorno salvaje; y segundo, se convierte en espacio para diseñar la estrategia militar librada en el monte que permita derrocar a Céfiro. En consecuencia, monte y jardín no se contraponen, sino que se transfieren algunas de sus propiedades.

Ante esta situación, es necesario crear otro espacio para enmendar la arbitrariedad sembrada por Cupido en la primera jornada: el palacio y los jardines de Pigmaleón. Aquí se resolverán los conflictos de libertad-destino y amor fisico-amor espiritual, a partir de la frustración del reinado de Anajarte y la venganza de Cupido. De este modo, por una parte, la victoria de Ifis tras la contienda en el espacio latente del monte quedará anulada con la transformación de Anajarte en mármol; por otra parte, el descubrimiento de Irífile como heredera del trono de Trinacria y la conversión de la estatua en mujer darán el triunfo al amor correspondido.

\section{EL JARDÍN Y EL CUMPLIMIENTO DEL DESTINO}

Es habitual encontrar en Calderón personajes ocultos a causa de una profecía, como ocurre en La vida es sueño, La hija del aire, El monstruo de los jardines o Eco y Narciso. Los individuos que se hallan en esta situación se ven cercados por un espacio que acaban rebasando. En Apolo y Climene, la princesa es un personaje privado de libertad por temor a que engendre a quien arrase Etiopía, asunto preexistente al argumento de la

${ }^{17}$ Calderón, La fiera, el rayo y la piedra, p. 330, vv. 2907-2908. 
obra. Sin embargo, la preocupación prioritaria para la protagonista no es salir de ese espacio, «medio templo y medio alcázar» ${ }^{18}$, sino, como sacerdotisa de Diana, mantenerlo inquebrantable ${ }^{19}$. Por eso, trata de descubrir quién ha entrado en el jardín del templo de la diosa y qué dama lo ha consentido. En el transcurso de acción, el pueblo reclama la libertad de su heredera, cuyo padre, Admeto, le requiere que mantenga el voto de castidad. Paralelamente a estos hechos, Apolo cae desde el cielo en una mina que comunica el recinto sagrado con el exterior y se enamora de Climene, bajo la apariencia de un pastor. La princesa, después de una serie de equívocos, es relacionada con Apolo por sus damas, quienes no dudan en acusarla ante Admeto de haber faltado a su compromiso.

La tercera jornada supone un cambio de espacio y de acción. Apolo y Climene huyen, atraviesan un río y se esconden en el palacio del mago Fitón. Entre tanto, el resto de personajes no cejará en su empeño de hallar a la joven fugada. Al final de la obra, descubrimos que Júpiter expulsó a Apolo por haber matado a los cíclopes y que ya ha sido perdonado. Como Diana no indulta a Climene, el dios del sol deberá decidir si regresa a su esfera natural o se queda con su amada.

A tenor de lo expuesto, el argumento nos muestra dos lugares de acción y dos conflictos propios del teatro calderoniano. En las dos primeras jornadas se presenta la oposición libertad-destino, vinculada a Climene y a su jardín. Junto a ello, podemos destacar la correlación ofensa-venganza, que subyace al conflicto principal y que, en el desarrollo de la acción, permite recuperarlo con más fuerza. En la tercera jornada, prosigue la lucha por burlar el destino, en cuya resolución interviene el amor. Este sentimiento está asociado desde el principio al jardín de Fitón, como lo revelan las palabras de Climene hacia Apolo: «venid conmigo, que quiero / de aquestos nuevos jardines / gozar los pensiles bellos $»^{20}$. Por otro lado, el tema de la caída de Apolo evoluciona

18 Calderón, Comedias, IV, Cuarta Parte de Comedias, p. 1080.

19 Vara López, 2014, se detiene en el tratamiento de la pérdida del recato, en la «caída» de la dama en el jardín, que se refleja mediante un lenguaje y unas imágenes de raíz cancioneril y petrarquista en Peor está que estaba y El galán fantasma. En Apolo y Climene no hallamos diálogos de tal complejidad simbólica, pero sí la intención de la protagonista de participar veladamente en el juego amoroso: "y si, puesto que el decirle / que osado al jardín vuelve, / seré yo a la que halle, fue / decirle que vuelva, deje / al trance de lo futuro / resultas de lo presente; / y vamos a que ya era / hora de venir, si hubiese / de venir [...]» (Calderón, Comedias, IV, Cuarta Parte de Comedias, p. 1097).

${ }^{20}$ Calderón, Comedias, IV, Cuarta Parte de Comedias, p. 1153. 
hasta presentar el enfrentamiento interno deber-amor, asociado al dios y al jardín mágico.

\begin{tabular}{|c|c|c|c|c|c|c|}
\hline \multirow{2}{*}{ 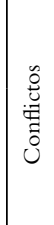 } & \multicolumn{4}{|c|}{$\begin{array}{l}\text { LIBERTAD / } \\
\text { DESTINO }\end{array}$} & \multicolumn{2}{|c|}{$\begin{array}{l}\text { TRIUNFO } \\
\text { DEL DESTINO }\end{array}$} \\
\hline & \multicolumn{3}{|c|}{ Activación } & \multicolumn{2}{|l|}{ Reactivación } & $\begin{array}{l}\text { DEBER- } \\
\text { AMOR }\end{array}$ \\
\hline \multirow{3}{*}{ 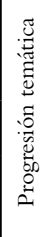 } & $\begin{array}{l}\text { Ofensa- } \\
\text { venganza de } \\
\text { Climene }\end{array}$ & $\begin{array}{l}\text { Caída de } \\
\text { Apolo }\end{array}$ & $\begin{array}{l}\text { Liberación de } \\
\text { Climene }\end{array}$ & $\begin{array}{c}\text { Ofensa-vengan- } \\
\text { za de Diana }\end{array}$ & $\begin{array}{l}\text { Unión de los } \\
\text { amantes }\end{array}$ & $\begin{array}{l}\text { Ascenso } \\
\text { de Apolo }\end{array}$ \\
\hline & \multicolumn{2}{|c|}{ Jardín de Climene } & \multicolumn{2}{|c|}{ Jardín de Climene } & \multicolumn{2}{|c|}{ Jardín de Fitón } \\
\hline & \multicolumn{2}{|c|}{ Jornada I } & \multicolumn{2}{|c|}{ Jornada II } & \multicolumn{2}{|c|}{ Jornada III } \\
\hline
\end{tabular}

El primer jardín está consagrado a Diana, de ahí que no admita la recreación amorosa; no obstante, el subterfugio de la mina ${ }^{21}$ posibilita los encuentros furtivos entre Flora y Céfiro y los desplazamientos de Apolo para requebrar a Climene. Este palacio y sus jardines son considerados por Climene, sabedora de su destino, como una cárcel: «sin que sea / consuelo para no ser / infausta prisión estrecha / ver plateado el calabozo/ ni dorada la cadena ${ }^{22}$. Pero su sufrimiento tiene un origen más profundo: «el más hondo calabozo / de las cárceles del pecho» ${ }^{23}$.

Dos son los momentos que perturban a Climene: las sombras de alguien que entró en sus jardines y la caída del sol. Esto último anticipa su destino y la atormenta: describe con tanta fuerza la caída del sol que altera su ánimo y sus sentidos hasta el punto de sentir que ella misma se abrasa. Cintia le hace ver que tanto esta visión como la del hombre que

${ }^{21}$ Acerca de la mina en Calderón, ver Rull, 2002. El autor establece las funciones de este espacio a partir de su carácter dinámico, frente a la gruta, y precisa que puede ser "vehículo de estrategia militar» o de una "acción misteriosa, de confusión y de sorpresa", caso, este último, ante el que nos encontramos. Por otra parte, el investigador establece una asociación entre El galán fantasma y Apolo y Climene en cuanto a las funciones de la mina: como vía de comunicación entre amantes y como elemento que lleva consigo la idea de fatalismo. Lo anterior nos remite al análisis que Iglesias Iglesias, 2013, hace del jardín minado en El galán fantasma.

22 Calderón, Comedias, IV, Cuarta Parte de Comedias, p. 1042.

${ }^{23}$ Calderón, Comedias, IV, Cuarta Parte de Comedias, p. 1070. 
entró en su recinto son ilusiones provocadas por su confinamiento, a lo que Climene replica:

Cesa,

Cesa, no prosigas, que es muy atrevida licencia pensar que yo... Mas no quiero que por mí mi enojo vuelva, sino mi razón. Entremos en la primer experiencia: de la ilusión del sol, Cintia, nacida de que aborrezca la luz solo por ser luz, me cobré.Y lo mismo hiciera de desotra ilusión a no darla tú ahora más fuerza ${ }^{24}$.

Climene admite como mero espejismo ver al sol despeñándose de día; en cambio, le da veracidad a las sombras que distingue de noche. Este jardín ${ }^{25}$ es, fundamentalmente, un espacio que contiene enredo: la argucia de Climene para conocer lo que sucedió allí la noche anterior provoca la entrada y salida de la mina de personajes que, en medio de la confusión, revelan la existencia de este espacio subterráneo y que Flora y Céfiro se veían a escondidas.

Calderón juega con la materia mitológica y transforma los presupuestos platónicos, ofreciéndonos en una caverna a alguien que representa la idea suprema, el Sol, pero que, con su caída en la mina, se siente desconocido, «despeñado» de sí mismo. Por ello, se siente fascinado por el entorno al que llega y se deja deslumbrar por la belleza de la joven. Pero si Apolo sufre una transformación al pasar por la gruta, Clime-

${ }^{24}$ Calderón, Comedias, IV, Cuarta Parte de Comedias, pp. 1052-1053.

${ }^{25}$ Alvarado Teodorika, ed. de La dama y el galán Aquiles (El monstruo de los jardines), 2013, p. 79, ejemplifica las funciones del jardín en Apolo y Climene con exigüidad. Del primero afirma que «antes de ser espacio de correspondencia amorosa es el lugar del enredo y el equívoco amoroso; en cuanto al segundo, jardín en el que Apolo y Climene viven su amor en nupcias, es el jardín dentro de la gruta». En nuestro estudio, destacamos el enredo en el primer jardín y reservamos la función como espacio de amor para el segundo, al que añadimos el valor de reflexión. 
ne hace lo propio al atravesar el río ${ }^{26}$. Este elemento, además, marca la frontera hacia un mundo de fantasía, donde el dramaturgo moldea los preámbulos del nacimiento de Faetón, inexistentes en el mito.

La princesa, ya en el nuevo espacio, cae desmayada en un risco y, al ruido de voces, Apolo duda si llevársela o dejarla allí. Entonces aparece Fitón y se compromete a salvar a Climene y a burlar su sino, pero sigue considerando que se halla en una prisión ${ }^{27}$.Veamos qué sensaciones le produjo la caída de Apolo en el primer jardín y cómo, después, al mencionarla el dios para explicar qué la motivó, se convence de que nada podrá hacer el mago por ella:

\section{Jardín de Climene}

¿No veis, no veis que su carro,
de la continua tarea
errando el curso y cayendo
precipitado a la tierra,
abrasa montes y mares,
de cuya encendida hoguera
son las espumas cenizas
y las montañas pavesas?
¿Que me quemo! ¡Que me abraso!
Pero ¿qué digo? ¿Qué idea
tan vana! ¡Qué fantasía
tan loca! ¡Qué ansia tan necia!
Arrebatome el dolor
vida y voz.
$\quad$ (Cuarta Parte
$\quad$ de Comedias, p. 1052)

Jardín de Fitón

\section{No}

lo digas, no lo pronuncies; que en vez de que el desengaño me alivie, hace que me angustie la memoria desa noche, pues fue la misma que tuve entre las vagas ideas que en la prisión me consumen la del despeño del sol. $\mathrm{Y}$ viendo que agora se unen despeño e idea, no sé la razón con que me arguye el temor de imaginar que la amenaza se cumple de mis hados, pues el fuego que en mi sentido introduces de aquella esperada ruina... (Cuarta Parte de Comedias, p. 1146)

En su jardín, a Climene la visión del sol despeñándose le producía desasosiego, pero es en el de Fitón donde ella recuerda, donde lo que antes fue captado difusamente por los sentidos ahora aparece como algo

${ }^{26}$ Cirlot, 2007, p. 391, señala como uno de los sentidos de «río» el de «transcurso irreversible y, en consecuencia, el abandono, el olvido».

${ }^{27}$ Para un análisis de este espacio, ver Parker, 1964, pp. 152 y ss. El investigador opone la cárcel al sol e interpreta a Apolo como la razón y a Climene como compulsión al amor, incitada por Fitón. 
inteligible $e^{28}$. Aquí se muestra temerosa de su destino y, poco después, insta a Apolo para que retorne a su imperio. Del mismo modo, el dios rememora en este espacio su vida pasada y se debate entre permanecer en la tierra o regresar al cielo. Consideramos, por ello, que el jardín mágico es lugar de desarrollo de las potencias del alma (entendimiento, memoria y voluntad $)^{29}$ y que la reflexión que conlleva por parte de los protagonistas surge desde su pasión, motor del verdadero conocimiento.

Poco después, Iris y Mercurio ascienden con Apolo a su esfera natural, sin Climene, que no ha obtenido el perdón de Diana. El efecto maravilloso se prolonga hasta el final de la obra, cuando varios personajes sufren sus efectos para evitar que informen a Admeto de dónde se encuentra su hija: Clicie, antigua amante de Apolo, se transforma en flor y Céfiro, en viento, al que se une después Flora. Sátiro es el único que no desaparece, pero cambia de aspecto, de acuerdo con su nombre dionisíaco. Seguidamente, el mago anuncia la continuación de la historia, con el nacimiento de Faetón.

\section{Un Jardín Nocturno para Psiquis y Cupido}

Un lugar de paso en la isla de Gnido acoge las idas y venidas de las hijas del rey Atamas: Selenisa, Astrea y Psiquis, que se dirigen hacia el templo de Venus, espacio latente que dinamiza la acción. Mientras tanto, Arsidas y Lidoro, futuros esposos de las dos primeras, observan sin ser vistos a las damas y quedan prendados de Psiquis.

La belleza de la joven ha enojado a la diosa del amor, quien anuncia que un monstruo será su dueño. El rey, siguiendo los designios de Júpiter, habría de sacrificarla en el monte Oeta, pero acabará abandonándola en un lugar más próximo. El traslado de la trama a otra isla y al espacio mágico que contiene supone un cambio brusco que se suaviza con dos niveles de transición: el mar, como recurso de distanciamiento de la realidad, y la mina, como medio de acceso al palacio de Cupido.

\footnotetext{
${ }^{28}$ Aparte de las similitudes entre Climene y Segismundo, en el monólogo de la joven previo a su liberación, apuntamos el recurso a la memoria como medio que en ambos casos permite distinguir el sueño de la realidad. Sobre este hecho en Segismundo, ver Morón, ed. de La vida es sueño, 1986, p. 53 y ss.

${ }^{29}$ Acerca de las potencias del alma, ver Frutos, 1981, pp. 147-326.
} 
Thomas Austin O'Connor ${ }^{30}$ precisa los temas que se advierten en la comedia. Así, explica cómo si en la primera jornada es dominante el binomio ofensa-venganza, en la segunda se presenta el amor como fuerza capaz de "vencer al hado", y en la tercera, junto a la necesaria relación entre amor y confianza, se trata el sufrimiento como «única vía redentora». En la siguiente tabla exponemos una síntesis de cómo progresa el conflicto principal (libertad-destino) a través de los temas desarrollados en la acción y de la complejidad que adquiere antes de resolverse, con la subordinación de un conflicto interno ${ }^{31}$ de Psiquis (libertad-tentación):

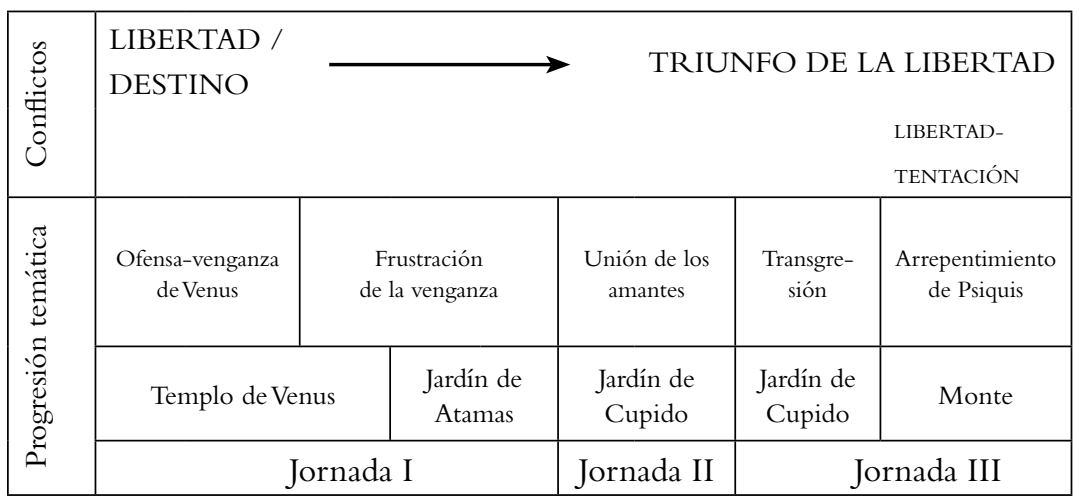

El primer conjunto palacio-jardín está asociado a Atamas. Aquí se invierte la situación del comienzo de la obra, pues ahora son Selenisa y Astrea las que se esconden para ver a los galanes, mientras ellos, guiados por Friso, recorren el jardín. Las dos damas quedan impactadas por la belleza de Cupido, el último en dar el paseo.

El jardín de Atamas es caracterizado por el gracioso de forma múltiple: un espacio metateatral, un "verde laberinto», un «hermoso paraíso»

${ }^{30}$ O'Connor, 1983.

${ }^{31}$ Obsérvese cómo si el conflicto primario enfrenta al libre albedrío con una instancia superior, ahora el antagonista se encuentra en el plano terrenal. Señalamos, por otra parte, que la dualidad libre albedrío-tentación la hallamos con frecuencia en el teatro religioso. En este sentido, Rull, 1983, p. 759, explica que el concepto del mundo en Calderón se establece atendiendo a dos hechos: «1) a la formación teológica del autor, y 2) a su firme convicción de que el mundo se atiene a lo dispuesto en el orden sobrenatural por Dios». El ser humano, por tanto, es libre «en el terreno puramente individual y temporal», pero tiene una limitación en el plano sobrenatural, «que son los planes de Dios, los cuales no puede modificar». Solo así es posible conjugar el libre albedrío y la providencia divina. 
y una esfera reservada a la mujer («este jardín no se cierra, / porque él se guarda a sí mismo, / que es donde suelen estar / las princesas») ${ }^{32}$. Es, por añadidura, abundante en cuadros, fuentes y estatuas y tiene dos accesos que permiten el juego de Friso, lo que se infiere cuando - después de haber entrado los galanes en el jardín - el gracioso le indica a Arsidas: "habréis de salir por un postigo" y a Lidoro: "volveré por vos luego» ${ }^{33}$. La idea de jardín como paraíso se refuerza con la declaración de Cupido como áspid que saldrá de entre las flores para acabar con la vida de Psiquis cuando esta duerma. No obstante, momentos después de contemplar su belleza, será él quien muera de amor.

La segunda jornada presenta el ambiente de la isla en la que es abandonada la joven, ante la desesperación de su primo y pretendiente Anteo. El paisaje es agreste y está caracterizado por el monte, que oculta un suntuoso palacio. Una galería prepara a Psiquis para penetrar en un espacio regido por nuevas normas y cuya visión la deslumbra inicialmente:

$$
\begin{aligned}
& \text { Cuando imaginé que el centro } \\
& \text { de la tierra me escondía } \\
& \text { a nunca más ver el día, } \\
& \text { ¿hallo tantas luces dentro? } \\
& \text { ¡Qué alcázar tan eminente! } \\
& \text { ¡Qué suntuoso palacio! } \\
& \text { ¡Qué verde, florido espacio! } \\
& \text { ¡Qué hermosa, lucida gente! }{ }^{34}
\end{aligned}
$$

Las escenas del jardín de Cupido están dominadas por la oscuridad, pues el requisito del dios para que ese espacio se mantenga es que Psiquis no pregunte por su identidad ni trate de verlo. El diálogo amoroso se da en estas condiciones y fragua la función principal del jardín.

La tercera jornada, que contiene escenas de distensión protagonizadas por Friso y Flora, introduce la presencia simultánea de dos espa$\operatorname{cios}^{35}$. Los jardines de Cupido se iluminan con las luces, danzas y cantos del palacio de Atamas, donde se están celebrando las bodas de Astrea y

32 Calderón, Comedias, III, Tercera Parte de Comedias, p. 835.

33 Calderón, Comedias, III, Tercera Parte de Comedias, p. 836.

${ }^{34}$ Calderón, Comedias, III, Tercera Parte de Comedias, p. 869.

${ }^{35}$ Cancelliere, 2013, p. 33, interpreta acertadamente esta escena como tópico de la vida como sombra, como teatro. 
Selenisa. Cupido, después de proyectar esta visión, advierte la tristeza de Psiquis y consiente que vaya su familia a visitarla. Es entonces cuando la acucian las dudas, provocadas por los recelos de sus hermanas, y Psiquis rompe su prohibición en una escena simétrica a la sucedida en el jardín de Atamas, cuando la joven era observada por Cupido mientras dormía. En esta ocasión, Psiquis, con una luz y un puñal contempla al dios inerme. El dios despierta sobresaltado, reprochándole que con la luz haya hecho sabedora a Venus de su escondite y sentenciando:

Y puesto que tú has querido

Cubrir, por antojo leve,

Hoy tanto fuego de nieve,

Tanta memoria de olvido,

para siempre me despido

de todo aqueste horizonte;

y así, a olvidarme disponte,

mirando en cuán breve espacio

se desvanece el palacio

y vuelve el monte a ser monte ${ }^{36}$.

Cupido exterioriza sus emociones a partir de la aniquilación del espacio compartido con Psiquis. Del mismo modo que se cubre «tanto fuego de nieve / tanta memoria de olvido", el palacio y los jardines humanizados por la princesa desaparecen, y lo hacen sin dejar rastro ${ }^{37}$ : "¿Cómo ha faltado sin ruina / tanta fábrica eminente?» ${ }^{38}$. Pese a esta acción impetuosa y punitiva, la historia acaba felizmente, ya que Psiquis no solo consigue el perdón de Cupido, sino también el de Venus, lo que

${ }^{36}$ Calderón, Comedias, III, Tercera Parte de Comedias, p. 911.

${ }^{37}$ Cabe mencionar dos obras mitológicas de Calderón donde se destruye un entorno con jardines. En ambos casos, el desastre genera ruinas: El mayor encanto, amor, en su representación de 1635, y El monstruo de los jardines. En la primera, Circe, tras la marcha de Ulises, hace que Trinacria, sobre la que actúan en su demolición el fuego, el aire y la nieve, quede oculta con el velo aciago de la noche. Sobre los dos finales de Calderón para esta obra (1935 y 1968), ver Ulla Lorenzo, 2011. En la segunda, el paisaje desolador con el que se inicia la obra es lo que queda de un auténtico vergel que Tetis arrasó cuando fue forzada por Peleo. De este espacio, solo quedó en pie el templo de Marte; lo demás se dejó abandonado al antojo de la naturaleza. Para la vinculación entre ruinas y jardines, ver el estudio homónimo de Orozco, 1947.

38 Calderón, Comedias, III, Tercera Parte de Comedias, p. 912. 
conlleva la unión de los amantes y la promesa de que la princesa será amada eternamente.

\section{Conclusiones}

Calderón prioriza en las obras analizadas la función del jardín como marco para el amor. Así se advierte en La fiera, el rayo y la piedra, donde se produce el agotamiento simbólico del jardín de Anajarte, lo que hace necesaria su sustitución por otro espacio donde se resuelven los conflictos iniciales. Más relevante es el procedimiento de duplicación de jardines en Apolo y Climene y en Ni Amor se libra de amor, cuyas similitudes estructurales se condensan en la visión simétrica del conjunto de palacio y jardines reales frente al del palacio y jardines subterráneos y mágicos, separados por el elemento del agua. La profundidad de los segundos conjuntos no es solo fisica, sino que conlleva una mayor complejidad, pues en estos espacios afloran nuevos conflictos, que se supeditan al principal antes de que este se resuelva.

Los jardines de Climene y de Atamas tienen como función esencial la de generar enredo, pero también acogen la atracción por la belleza de las protagonistas, impulso neoplatónico que lleva a perseguir lo verdadero. El dilema que albergan se desencadena con la ofensa a los dioses, de la que no son responsables directas las protagonistas: en el de Climene, la acusación precipitada de haber roto su voto de castidad enoja a Diana y activa el cumplimiento de la profecía; en el caso de Psiquis, su belleza agravia a Venus y el pueblo aviva esta situación.

Los espacios de Fitón y de Cupido, ocultos en una esfera subterránea, son imprescindibles para el amor, lo único que puede salvar a las princesas. Ahora bien, las similitudes se aprecian hasta aquí, pues en la última jornada de cada obra, antes de conocer si triunfa la predestinación o la libertad, se plantean conflictos distintos, que solo los personajes pueden dirimir.

En Ni Amor se libra de amor, los jardines de Cupido enmarcan el amor sensual, que se disipa cuando Psiquis, instigada por sus hermanas, decide incumplir las normas. No obstante, su arrepentimiento conseguirá el perdón de su amante y de Venus y hará que se sublime y se eternice su pasión. En Apolo y Climene, la joven observa en su jardín sombras, reflejos, que pertenecen a la realidad sensible y cuando tiene la visión del sol precipitándose, se turba, pero no acierta a comprender lo que observa 
ni lo que siente. En cambio, los jardines de Fitón propician sus amores y, además, mueven a la reflexión. La comedia se cierra con un movimiento ascendente, pero solo por parte de Apolo, quien sube al reino de lo absoluto, anteponiendo el deber al amor. La princesa, por su parte, aunque queda atrapada en el mundo sensible, experimenta un progreso, pues las sombras del primer jardín regresarán a su memoria con mayor sensación de verdad ${ }^{39}$. Después de un breve viaje, y a la luz de las revelaciones de Apolo, Climene comprenderá lo inexorable de su destino en un espacio paralelo, en unos «nuevos jardines».

${ }^{39}$ Echandi Ercilla, 2000, establece una interesante correspondencia entre los jardines de Platón y los niveles de su teoría del conocimiento, que inspira esta última conclusión. 


\section{BiBLIOGRAFÍA}

Alvarado Teodorika, Tatiana, «El jardín en el teatro aurisecular. Las comedias mitológicas de Calderón", en Actas del XVI Congreso de la AIH: Nuevos caminos del hispanismo, coord. Pierre Civil y Françoise Crémoux, Madrid / Frankfurt, Iberoamericana / Vervuert, vol. 2, 2010, pp. 145-165.

Amezcua, José, «Notas sobre el espacio en algunas obras de Calderón», en Calderón. Actas del Congreso Internacional sobre Calderón y el teatro del Siglo de Oro, Madrid, 8-13 de junio de 1981, ed. Luciano García Lorenzo, Madrid, Centro Superior de Investigaciones Científicas, 1983, vol. III, pp. 1533-1543.

Arellano, Ignacio, «Espacios dramáticos en los dramas de Calderón», en Calderón: sistema dramático y técnicas escénicas. Actas de las XXIII Jornadas de Teatro Clásico de Almagro, ed. Felipe B. Pedraza Jiménez, Rafael González Cañal y Elena Marcello, Almagro, Ediciones de la Universidad de Castilla-La Mancha, 2001, pp. 77-106.

Arellano, Ignacio, «Espacios de maravilla en los dramas de Calderón», en Loca Ficta: Los espacios de maravilla en la Edad Media y Siglo de Oro, ed. Ignacio Arellano, Madrid / Frankfurt, Iberoamericana / Vervuert, 2003, pp. 41-56.

Calderón de la Barca, Pedro, Comedias, III, Tercera Parte de Comedias, ed. Don William Cruickshank, Madrid, Biblioteca Castro, Fundación José Antonio de Castro, 2007.

Calderón de la Barca, Pedro, Comedias, IV, Cuarta Parte de Comedias, ed. Sebastian Neumeister, Madrid, Biblioteca Castro, Fundación José Antonio de Castro, 2010.

Calderón de la Barca, Pedro, El príncipe constante, ed. Enrica Cancelliere, Madrid, Biblioteca Nueva, 2000.

Calderón de la Barca, Pedro, La dama y el galán Aquiles (El monstruo de los jardines), ed. Tatiana Alvarado Teodorika, Madrid / Frankfurt, Iberoamericana / Vervuert, 2013.

Calderón de la Barca, Pedro, La fiera, el rayo y la piedra, ed. Aurora Egido, Madrid, Cátedra, 1989.

Calderón de la Barca, Pedro, La vida es sueño, ed. Ciriaco Morón, Madrid, Cátedra, 1986.

Cancelliere, Enrica, «L'asse verticale della visione nel teatro di Calderón e nella pittura manierista", en Le arti figurative nelle letterature iberiche e iberoamericane. Atti del XIX Convegno della Associazione Ispanisti Italiani (Roma, 1618 settembre 1999), coord. Antonella Cancellier y Renata Londero, Padova, Unipress, 2001, pp. 77-86.

Cancelliere, Enrica, «Amor y Psique. Hermenéutica de una fábula de las artes figurativas al teatro de Calderón», en Fiestas calderonianas, ed. Alejandra Ulla Lorenzo, Anuario Calderoniano, vol. extra 1, 2013, pp. 21-48.

Cirlot, Juan Eduardo, Diccionario de símbolos, Barcelona, Siruela, 2007. 
Echandi Ercilla, Santiago, "Filosofias del jardín y sabidurías en el jardín», en La cultura del Barroco. Los jardines: arquitectura, simbolismo y literatura, Huesca, Instituto de Estudios Altoaragoneses, 2000, pp. 149-168.

Frutos, Eugenio, La filosofía de Calderón en sus Autos sacramentales, Zaragoza, Centro Superior de Investigaciones Científicas / Instituto Fernando del Católico, 1981.

Iglesias Feijoo, Luis e Isabel Hernando Morata, «Dualidad y paralelismos en Casa con dos puertas mala es de guardan, Anuario Calderoniano, 6, 2013, pp. 111-131.

Iglesias Iglesias, Noelia, «El jardín minado de El galán fantasma de Calderón», Atalanta: Revista de las Letras Barrocas, 1, 2, 2013, pp. 51-76.

LARA Garrido, José, «Texto y espacio escénico (El motivo del jardín en el teatro de Calderón)», en Calderón. Actas del Congreso Internacional sobre Calderón y el teatro español del Siglo de Oro, Madrid, 8-13 de junio de 1981, ed. Luciano García Lorenzo, Madrid, Centro Superior de Investigaciones Científicas, 1983, vol. II, pp. 939-954.

LARA GARRIDO, José, «El jardín y la imaginación espacial en el teatro barroco español», en La cultura del Barroco. Los jardines: arquitectura, simbolismo y literatura, Huesca, Instituto de Estudios Altoaragoneses, 2000, pp. 187-226.

LoBATo, María Luisa, "“Jardín cerrado, fuente sellada”: espacios para el amor en el teatro barroco», en En torno al Teatro del Siglo de Oro. Jornadas XXI-XXIII, ed. Antonio Serrano y otros, Almería, Instituto de Estudios Almerienses, 2007, pp. 199-219.

O’Connor, Thomas A., "El optimismo de Ni amor se libra de amon», en Calderón. Actas del Congreso Internacional sobre Calderón y el teatro español del Siglo de Oro, Madrid, 8-13 de junio de 1981, ed. Luciano García Lorenzo, Madrid, Centro Superior de Investigaciones Científicas, 1983, vol. I, pp. 533-540.

Orozco Díaz, Emilio, «Ruinas y jardines. Su significado y valor en la temática del barroco", en Temas del barroco, Granada, Universidad de Granada, 1947, pp. 118-176.

PARKer, Alexander A., "Metáfora y símbolo en la interpretación de Calderón», Actas del Primer Congreso Internacional de Hispanistas, Oxford, 6-11 de septiembre de 1962, coord. Cyril A. Jones y Frank Pierce, Oxford, Oxford University Press, 1964, pp. 141-160.

Porqueras-Mayo, Alberto, "La imagen de "La bella dormida" en el teatro de Calderón», en Hacia Calderón. Sexto Coloquio Anglogermano, Archivum Calderonianum, ed. Hans Flasche, Wiesbaden, Franz Steiner, 1983, vol. 2, pp. 48-64.

Rull Fernández, Enrique, «Hacia la delimitación de una teoría político-teológica en el teatro de Calderón", en Calderón. Actas del Congreso Internacional sobre Calderón y el teatro español del Siglo de Oro, Madrid, 8-13 de junio de 
1981, ed. Luciano García Lorenzo, Madrid, Centro Superior de Investigaciones Científicas, 1983, vol. II, pp. 759-767.

Rull FernánDEZ, Enrique, «El camino de la mina, vehículo de emociones en Calderón», Revista de Literatura, 64, 128, 2002, pp. 385-411.

Rull Fernández, Enrique, «El jardín en el teatro mitológico calderoniano», en Compostella aurea. Actas del VIII Congreso de la Asociación Internacional del Siglo de Oro (Santiago de Compostela, 1-11 de julio de 2008), coord. Antonio Azaustre Galiana y Santiago Fernández Mosquera, Santiago de Compostela, Universidad de Santiago de Compostela, 2011, vol. 3, pp. 413-420.

SuÁrez Miramón, Ana, «El jardín en los autos sacramentales de Calderón», en Actas del VII Congreso de Caminería Hispánica, Madrid, Ministerio de Fomento, 2006, formato CD-Rom, pp. 1-19.

Suárez Miramón, Ana, «Palacios fantásticos en Calderón», en Del Siglo de Oro y de la Edad de Plata. Estudios sobre literatura española dedicados a Juan Manuel Rozas, ed. Jesús Cañas Murillo y José Luis Bernal, Cáceres, Universidad de Extremadura, 2008, pp. 143-158.

Ulla Lorenzo, Alejandra, «Sobre la reescritura de los finales en las comedias de Calderón: Polifemo y Circe (1630) y El mayor encanto, amor (1635 y 1668)», en Compostella aurea. Actas del VIII Congreso de la Asociación Internacional del Siglo de Oro (AISO), Santiago de Compostela, 7-11 de julio de 2008, coord. Antonio Azaustre Galiana y Santiago Fernández Mosquera, Santiago de Compostela, Universidad de Santiago de Compostela, 2011, vol. 3, pp. 485-496.

VAra López, Alicia, «De flores, mitos y jardines. Algunas notas sobre la vulneración del recato femenino y sus consecuencias dramáticas en el lenguaje del primer Calderón», en Páginas que no callan: historia, memoria e identidad en la literatura hispánica, coord. Alejandro García Reidy, Luis María Romeu Guallart, Eva Soler Sasera y Luz Celestina Souto, Valencia, Universidad de Valencia, 2014, pp. 153-164.

Zugasti, Miguel, «El espacio del jardín en los Autos sacramentales, de Calderón», Revista Mosaicum, 13, 2011, pp. 47-56. 